UC-15

Issued: June 1982

LA- $-9432-H S$

DE82 019716

\title{
Nondestructive Verification of the Exposure of Heavy-Water Reactor Fuel Elements
}

\author{
J. R. Phillips \\ T. R. Bement \\ C. R. Hatcher \\ S. -T. Hsue \\ D. M. Lee
}

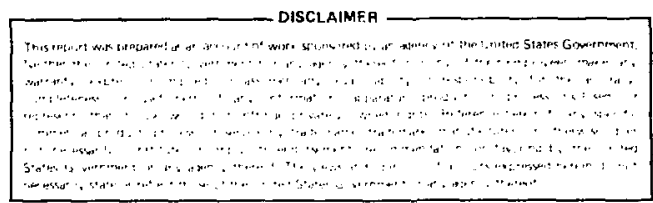




\section{CONTENTS}

ABSTRACT $\ldots \ldots \ldots \ldots$

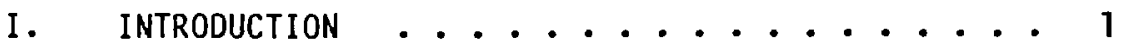

II. EXPERIMENTAL METHOD ............ 2

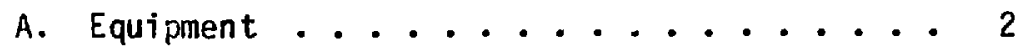

B. Procedure ........... 3

III. DISCUSSION .................. 3

A. Axial Gamma-Ray Profiles ........ 3

B. Relative Detection Efficiency Correction . . 6

C. Isotopic Correlations with Declared Exposure . 9

IV. CONCLUSIONS ...................... 10

ACKNOWLEDGMENTS ................... 13

REFERENCES .............. 13 


\title{
NONDESTRUCTIVE VERIFICATION OF THE EXPOSURE OF HEAVY-WATER REACTOR FUEL ELEMENTS
}

by

J. R. Phillips, T. R. Bement, C. R. Hatcher, S. $-T$. Hsue, and D. M. Lee

\begin{abstract}
Relative exposures of 137 irradiated heavy-water reactor fuel elements were determined from the measured fission product activities, using high-resolution gamma-ray spectrometry. Exposures ranged from 100 to $1000 \mathrm{MWd} / \mathrm{tU}$. Correlations between various gamma-ray signatures of specific fission products and operator-declared exposure values were calculated. Axial gamma-ray profiles were measured using intrinsic germanium, cadmium telluride, and ionization chanber detectors.
\end{abstract}

\section{INTRODUCTION}

One hundred and thirty-seven irradiated heavy-water reactor fuel elements were examined nondestructively using a high-resolution gamma-ray spectrometry system to verify the relative exposure values. Operator-declared exposure values ranged from 100 to $1000 \mathrm{MWd} / \mathrm{tU}$. All of the fuel elements were irradiated under identical conditions except for differences in relative exposures. All were discharged from the reactor at the same time; therefore, all the cooling times were identicai. The existence of this extremely large set of fuel elements provided a unique opportunity to evaluate the use of nondestructive gamma techniques for verification of declared exposure values.

The fuel examinations were performed at the 40-MW, natural-uranium, heavywater-moderated Taiwan research reactor (TRR). ${ }^{1}$ The fuel is uranium metal in an aluminum sheath supported wi thin a coolant tube having shielding sections 
at the top and bottom. Each fuel element contains $\checkmark 54 \mathrm{~kg}$ of natural uranium within a $3-\mathrm{m}$ section, with the overall length of the fuel rod being $210 \mathrm{~m}$.

\section{EXPERIMENTAL METHOD}

\section{A. Equipment}

Each irradiated fuel element was examined as it was loaded into the reactor core by using a specially designed collimation assembly that attached to the fuel transfer cask. A schematic of the collimation assembly (Fig. 1) shows the relative positions of the three gamma-ray detectors used: (1) an intrinsic yermanium detector, for collecting detailed gamma-ray spectra; (2) a cadmium telluride detector, set to measure only the gross gamma-ray signature above $200 \mathrm{keV}$; and (3) an air-filled ionization chamber, for measuring the total gamma dose of the fuel element.

The germanium detector surrounded by a lead shielding annulus was mounted on a rigid platform to maintain precise geometry throughout the measurement exercise. The primary collimating sit, $10 \mathrm{~mm}$ high by $70 \mathrm{~mm}$ wide by $270 \mathrm{~mm}$ long, defined precisely the volume segment of the fuel element from which the gamma-ray spectra were collected. Two additional beam-scraping collimators

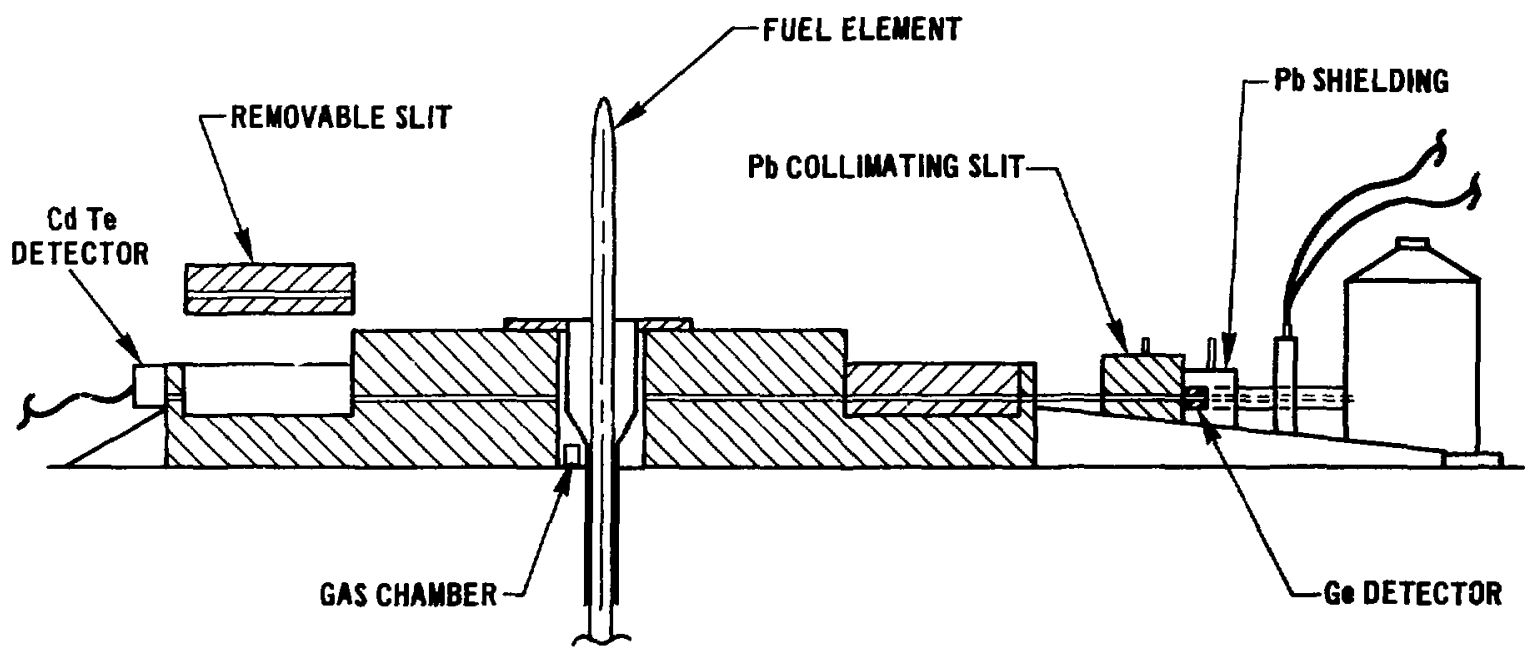

Fig. 1 .

Collimation assembly used to measure the irradiated fuel elements. 
plus lead and copper absorbers were used to reduce the gamma-ray signal to an acceptable level for data collection. A ${ }^{54} \mathrm{Mn}$ gamma-ray source was placed next to the germanium detector as an internal standard to be used for deadtime and pulse pileup correction. The net areas of all prominent gamma-ray peaks were measured and normalized using the ${ }^{54} \mathrm{Mn}$ source as the internal standard. The cadmium telluride detector was located opposite the germanium detector. Both cetectors measured gamma rays emitted from the same volume segment. The ionization chamber was placed adjacent to the centering device $(25 \mathrm{~cm}$ below the collimating slits) to obtain sufficient activity. As a result, the ionization chamber measured the gamma dose rate from a longer axial section of the fuel element than did the germanium or cadmium telluride detectors.

\section{B. Procedure}

The specific examination procedure involved the transfer of each irradiated fuel element in a shielded cask from the wet storage basin to the colliindion assembiy located on top of the reactor. Figure 2 shows the collimation assembly in position to receive a fuel element. The fuel transfer cask was positioned on top of the collimation assembly (Fig. 3). Then each fuel element was lowered into position for examination and subsequently lowered into the reactor core.

Each detector was used to measure the axial gamma-ray profile at seven positions (separated by $50 \mathrm{~cm}$ ) along the $305-\mathrm{cm}$ length of the active fuel region. Gamma-ray spectra $(340-2440 \mathrm{keV})$ were collected at the center axial position and stored on a magnetic disk for future analysis. A 1-s count of the gamma-rays above 150-keV was recorded from the germanium detector, whereas a 10-s collection period was used for the cadmium telluride detector. The response from the current output of the ionization chamber was nearly instantaneous.

\section{DISCUSSION}

\section{A. Axial Gamma-Ray Profiles}

Axial profiles obtained using the three different gamma-ray detectors are shown in Fig. 4 for three fuel elements with different exposures. The three sets of gamma-ray profiles show good agreement between the values measured by 


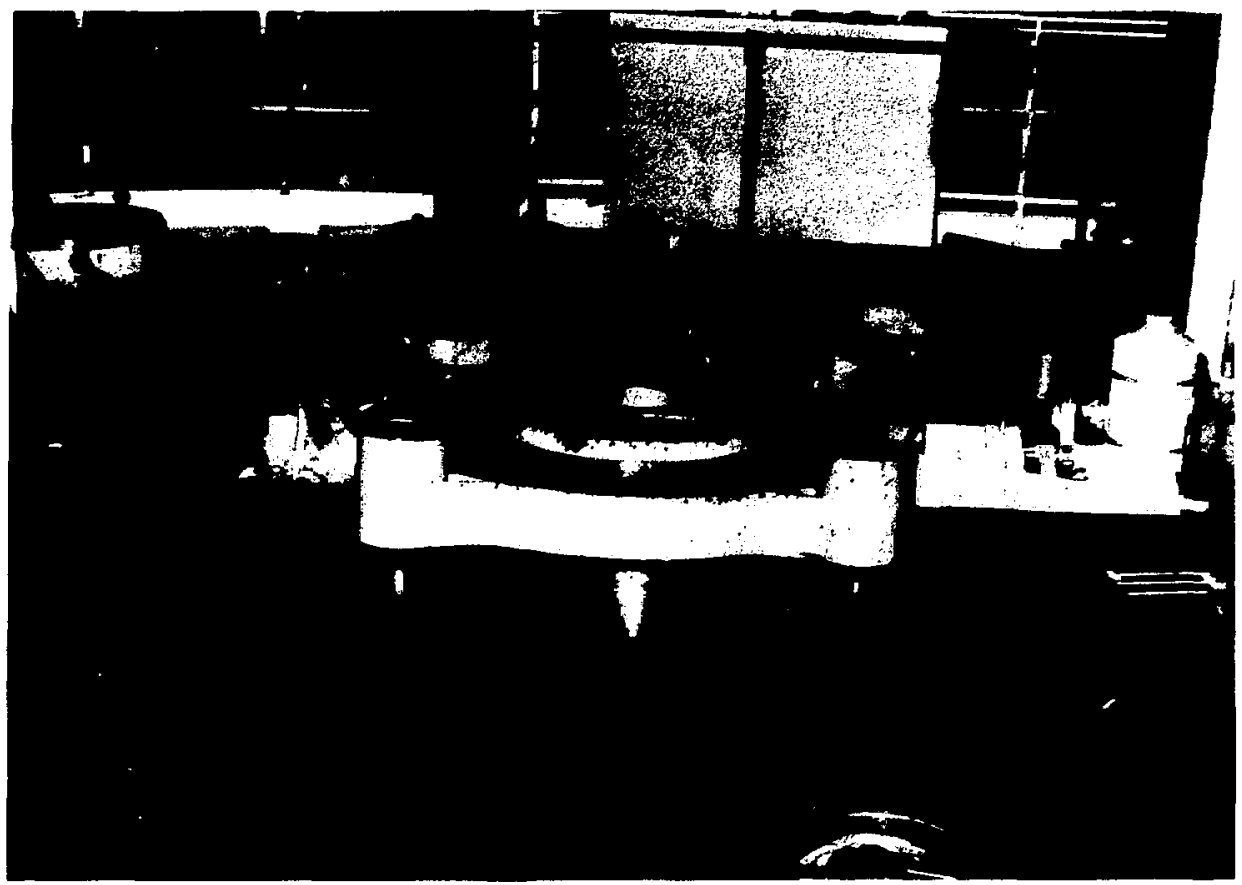

Fig. 2.

Collimation assembly on top of reactor core.

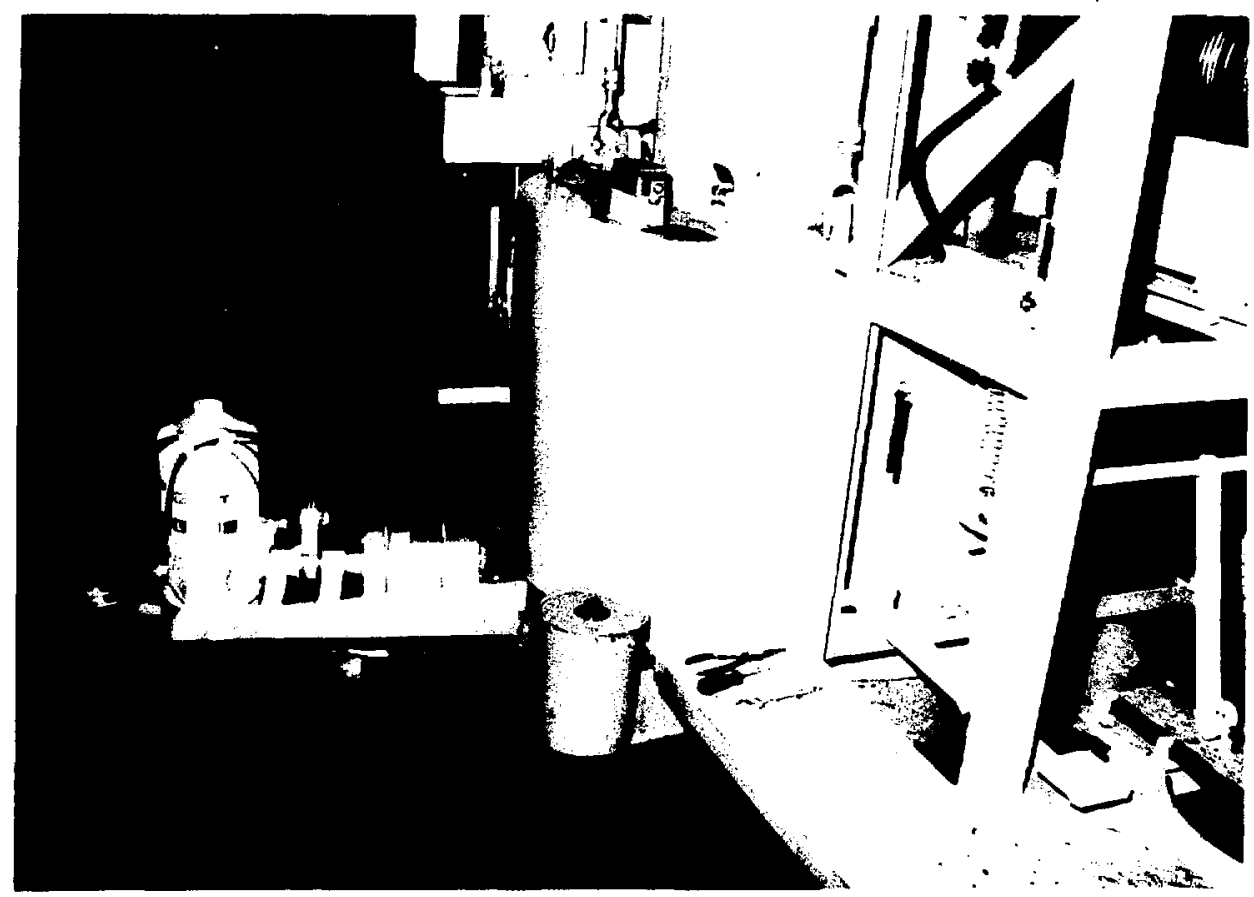

Fig. 3.

Collimation assembly with fuel transfer flask in position for scanning irradiated fuel element. 

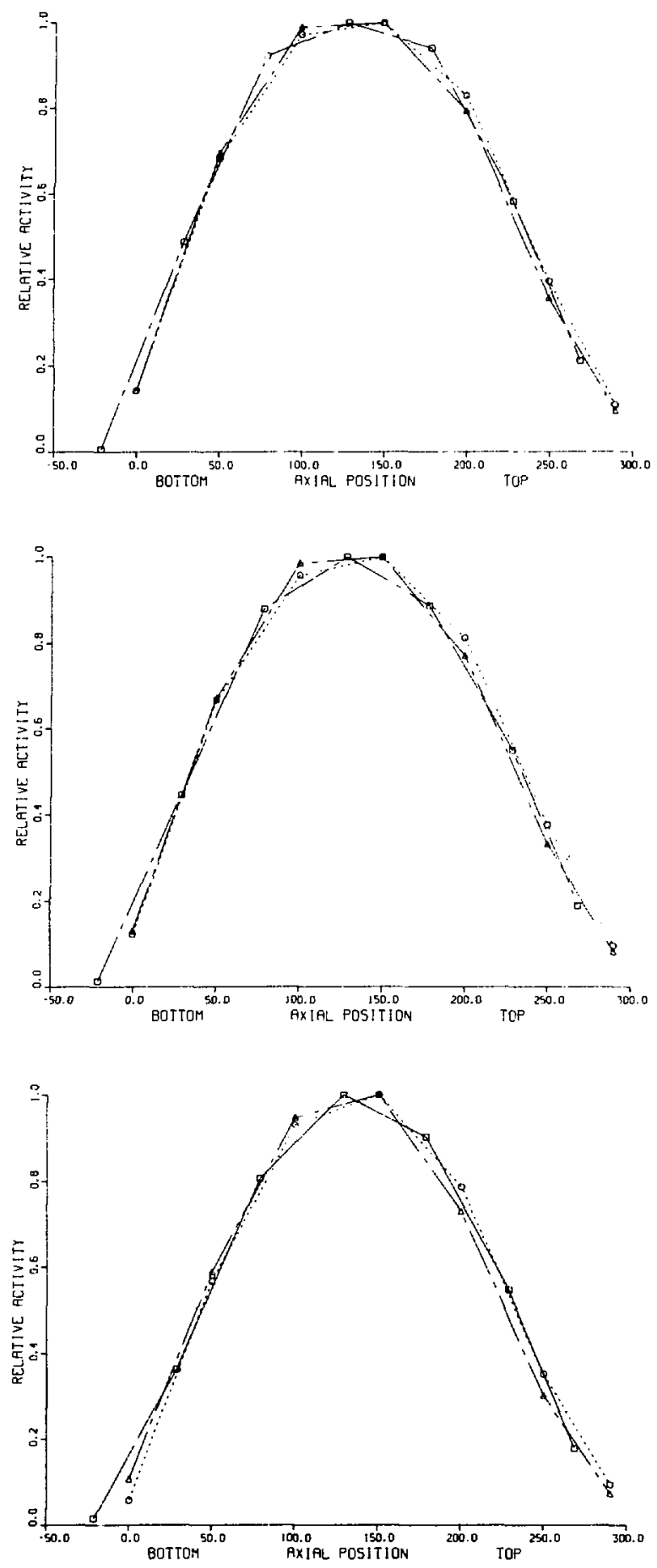

Fig. 4.

Nornalized axial profiles obtained using ionization chamber (口), germanium $(0)$, and cadmium telluride $(\Delta)$ detectors for fuel elements with exposures of 270, 580, and $990 \mathrm{MWd} / \mathrm{tU}$. 
the three detectors. The ionization chamber recorded the total gross gamma activity; the cadmium telluride and germanium profiles were obtained by setting a low-energy threshold $(2150 \mathrm{keV})$. As expected, the uncollimated profile from the ionization chamber is slightly broader than the other two activity profiles. The axial gross gamma-ray profiles were made to ensure that the spectral measurements were collected at the correct axial position.

\section{B. Relative Detection Efficiency Correction}

The gamma rays from a specific isotope can be used to determine the relative detection efficiency function for a specific scanning geometry. This function can be used to correct the isotopic ratio for differences in the total system geometry, resulting in a ratio that is independent of the scanning geometry. The relative detection efficiency for a specific measurement geometry at a particular gamma-ray energy can be defined as the relative probability of a gamma-ray escaping the fuel material, passing through any absorbing material, and producing a pulse in the full-energy peak. The relative detection efficiency function is then determined by dividing each full-energy peak area by its gamma-branching yield and expressing this ratio as a function of yamma-ray energy. ${ }^{2-5}$ This relative efficiency function is essentially the product of the detector efficiency and the sample attenuation expressed as a function of gamma-ray energy. By using this function, an isotopic ratio [for example, $\left.{ }^{134} \mathrm{Cs} /{ }^{137} \mathrm{Cs}(604.6 \mathrm{keV} / 661.5 \mathrm{keV})\right]$ can be corrected for differences in attenuation and efficiency for each gamma ray to obtain a ratio that is independent of these factors. In particular, the isotopes with multiple gamma-ray lines are used to obtain the relative detection efficiency.

If the scanning geometry remi ns constant for a set if measurements, changes in the efficiency functiol ould be indicative of changes in source self-attenuation caused by fuel element modification by source removal or substitution. A technique for rapid analysis of the gamma-ray spectra using a Hotellings- $T^{2}$-type statistic has been developed as a method of screening measurements performed on large sets of irradiated fuel elements and identifying possible outliers. ${ }^{6}$ Applied to this set of data to identify elements that should be examined in greater detail, the screening test correctly flagged fuel elements that had broken tension members. These broken tension members caused a slight downward shift in the fuel region, resu?ting in slightly different scanning geometries. The remaining number of fuel elements identified 
as possible outliers was within the expected limits for specified confidence levels.

Two functional forms of the relative detection efficiency function were analyzed: linear and quadratic. The analysis was based on a log-log plot of count rate divided by branching ratio vs gamma-ray energy for the ${ }^{134} \mathrm{Cs}$, ${ }^{144} \mathrm{Pr}$, and ${ }^{106} \mathrm{Rh}$ peaks listed in Table I. Assumptions used for the analysis included: (1) one of these functional forms is the true model describing the behavior of the data and (2) the failure of the data to follow exactly the true model is a result of the presence of random Gaussian errors with constant unknown variance. Figure 5 shows a comparison of these two models for three fuel elements with different levels of exposure: 270, 580, and $990 \mathrm{MHd} / \mathrm{tu}$. The results shown are typical of those obtained for the remaining 134 fuel elements. The curves were estimated using least-squares fitting techniques.

\section{TABLE I}

GAMMA-RAY ENERGIES AND BRANCHING YIELDS

\begin{tabular}{lcc} 
Isotope & $\begin{array}{c}\text { Energy } \\
\text { (keV) }\end{array}$ & $\begin{array}{c}\text { Relative } \\
\text { Branching Yiel da }\end{array}$ \\
\hline${ }^{134} \mathrm{Cs}$ & 604.6 & 0.976 \\
$795.8+801.8$ & 0.941 \\
1365.1 & 0.0304 \\
${ }^{144} \mathrm{Pr}$ & 696.5 & 0.0135 \\
& 1489.1 & 0.0027 \\
& 2185.7 & 0.0067 \\
$106_{\mathrm{Rh}}$ & 621.8 & \\
& 873.1 & 0.0975 \\
& 1050.1 & 0.00414 \\
1128.0 & 0.015 \\
& 1562.0 & 0.00383 \\
& & 0.0015
\end{tabular}

Data taken from Refs. 7 and 8. 


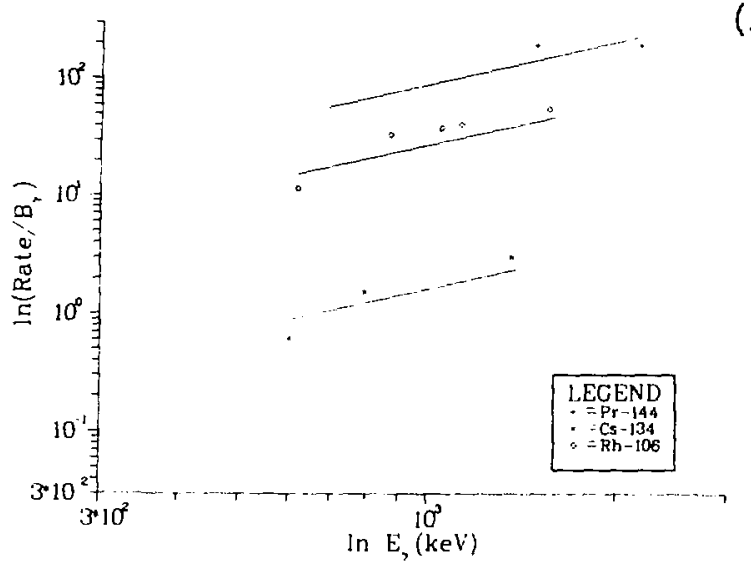

(A)
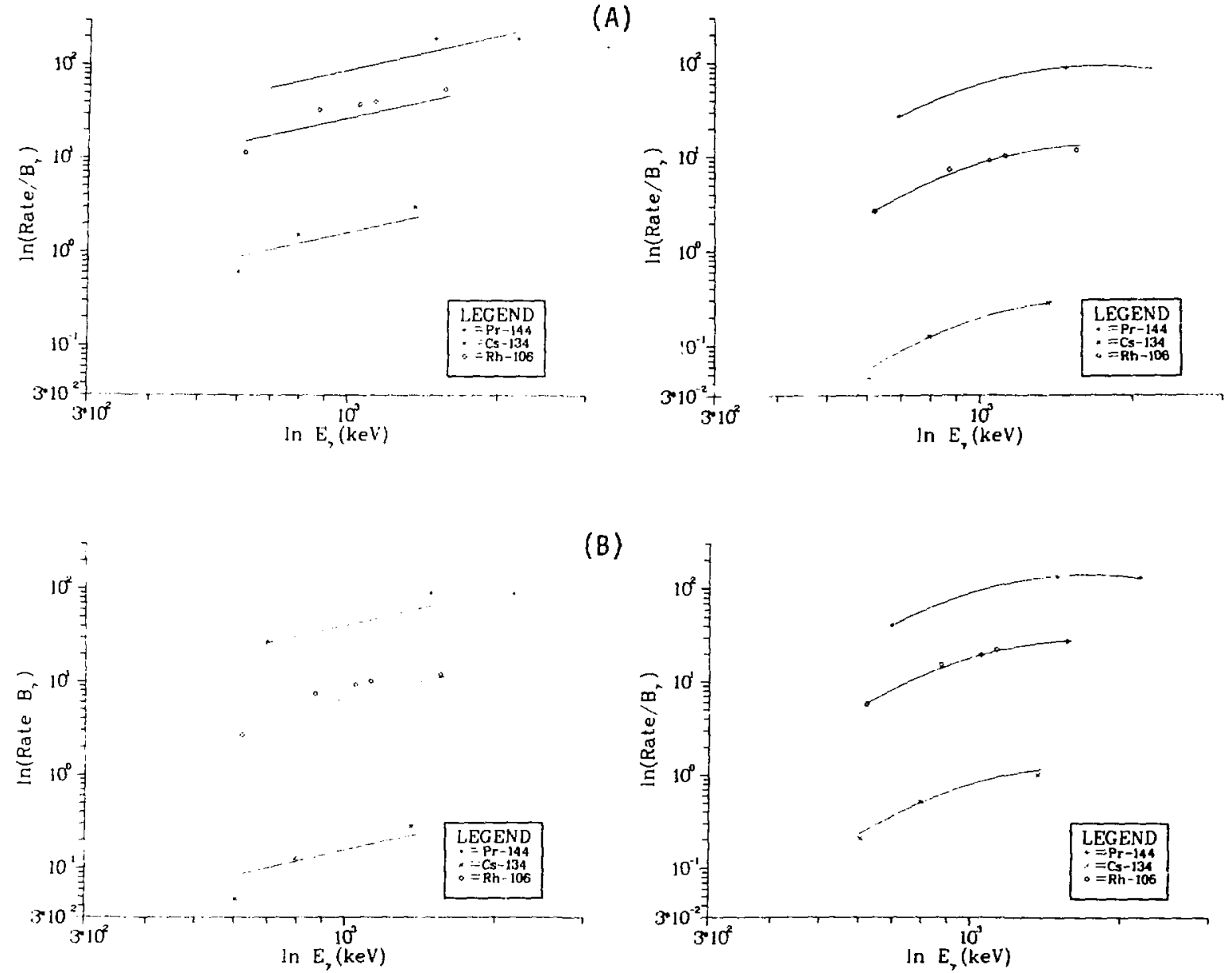

(8)
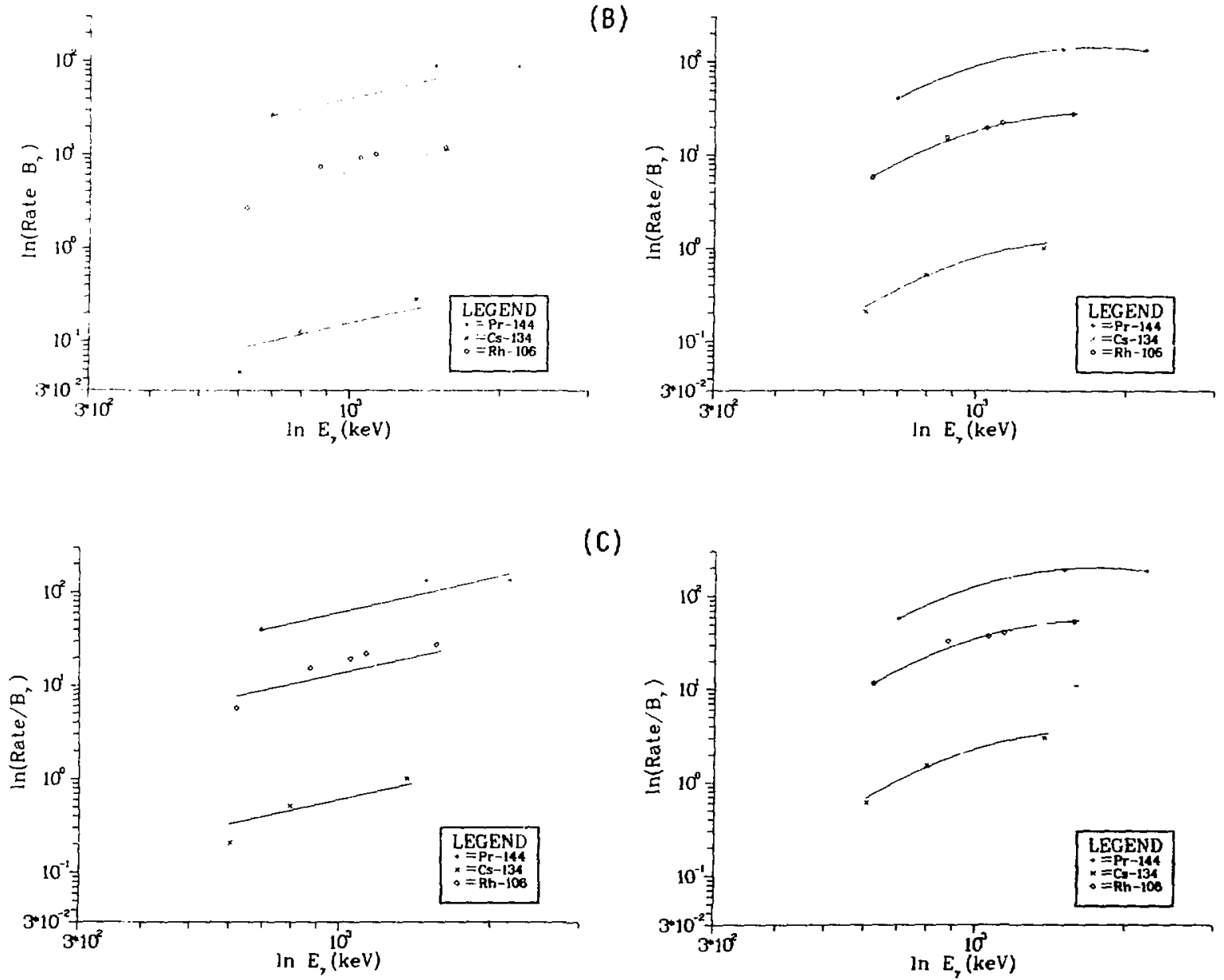

(c)

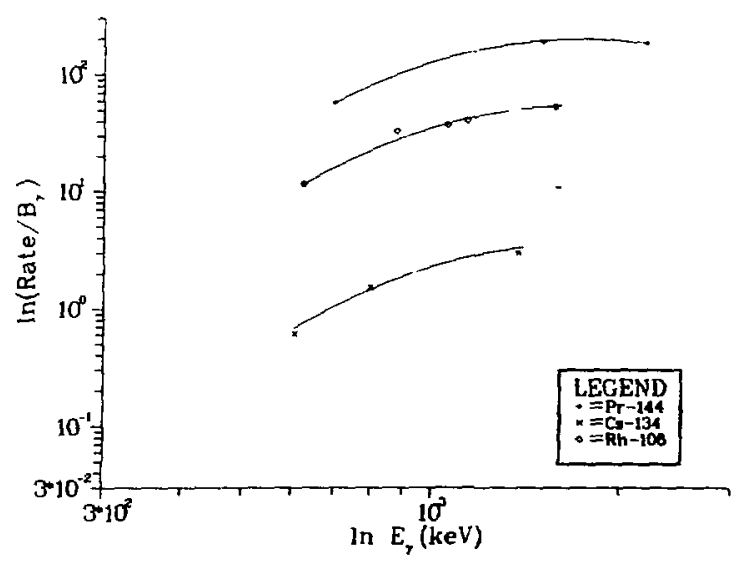

Fig. 5 .

The linear and quadratic functional relationships of in (Rate/B $\gamma$ ) vs in $E_{\gamma}$ for three fuel elements with exposures of (A) 270 , (B) 580 , and (C) $990 \mathrm{Mdd} / \mathrm{tU}$. 
Several specific efficiency correction functions were considered. These included functions based soiely on the ${ }^{134} \mathrm{Cs}$ data, the ${ }^{144} \mathrm{Pr}$ data, and the ${ }^{106} \mathrm{Rh}$ data, and on data from a combination of these three isotopes. In the least-squares fit of a particular function, the coefficients were constrained to have the same value for a11 137 fuel elements. Thus, each least-squares fit in effect established a slope (for linear fits) or curvature (for quadratic fits) that was constant over all fuel elements. For a particular furiction, only the intercept changed from one fuel element to the next. In both the linear and quadratic cases, tests of the hypotheses indicated that the coefficients (that is, slopes or curvatures) were not the same for all three isotopes. It was also determined that quadratic functions fit significantly better than linear functions.

Each of the three single-isotope quadratic functions lobtained singly from the ${ }^{134} \mathrm{Cs}$ data, the ${ }^{144} \mathrm{Pr}$ data, and the ${ }^{106} \mathrm{Rh}$ data) was tested to see how well it fit the entire data $s \in t$. The sum of squared differences of observed log count rates from predicted log count rates was used as a basis of comparison. Table II shows the sum of squares for each of the energy peaks used in obtaining the least-squares fits. The ${ }^{106}{ }_{R h}$ function fit the data best, with the ${ }^{144} \mathrm{Pr}$ function a close second. The ${ }^{134} \mathrm{Cs}$ function did the poorest job of predicting count rate at the energy peaks listed in Tabie II. However, if we consider predictive ability only in the $605-$ to $873-\mathrm{keV}$ range, the ${ }^{134} \mathrm{Cs}$ curve is the best predictor in every case except the ${ }^{144} \mathrm{Pr}$ 696-keV peak. Because of $i$ ts predictive ability in this range, the ${ }^{134}$ Cs curve was used to make efficiency corrections. Also, ${ }^{134} \mathrm{Cs}$ is one of the two isotopes in the isotopic ratio ${ }^{134} \mathrm{Cs} /{ }^{137} \mathrm{Cs}$ used in the correlation with operator-declared values of burnup.

\section{Isotopic Correlations with Declared Exposure}

The correlation between the ${ }^{\sqrt{37}} \mathrm{Cs}$ isotopic activities and the operatordeclared exposure values is shown in Fig. 6. The calculated least-squares regression line with $95 \%$ confidence bounds is also shown. ${ }^{9}$ These confidence bounds may be interpreted as defining a region within which the experimenter is $95 \%$ confident that an individually measured value for ${ }^{137}$ Cs will fall for a specified exposure value.

Figure 7 shows similar results for the ${ }^{134} \mathrm{Cs} /{ }^{137} \mathrm{Cs}$ isotopic ratio and the operator-declared exposure values. The relative efficiency differences for the 


\section{TABLE II}

SUM OF SQUARED RESIDUALS USING THREE DIFFERENT QUADRATIC FUNCTIONS

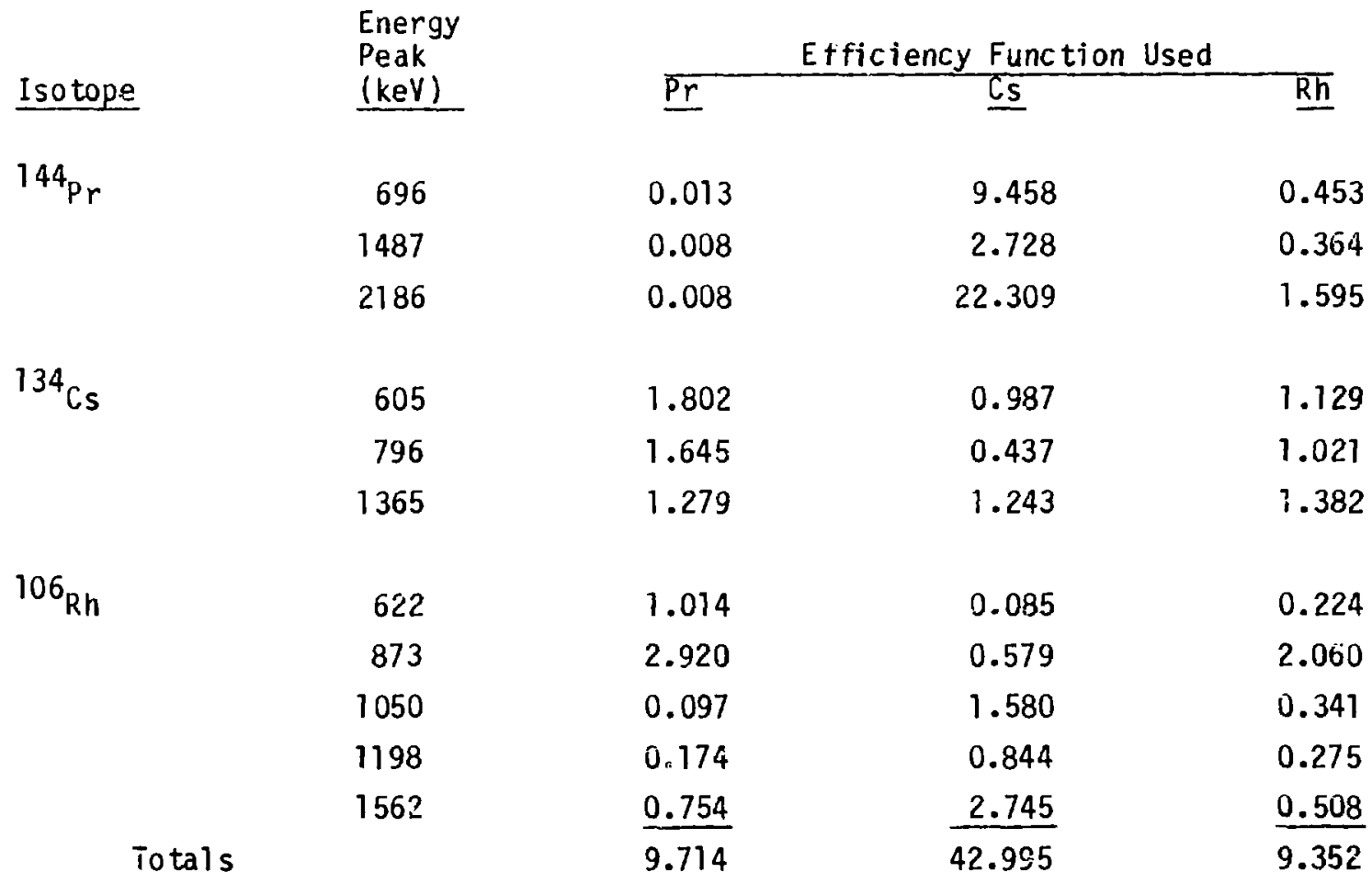

two gamma rays, $604.6 \mathrm{keV}$ for ${ }^{134} \mathrm{Cs}$ and $661.6 \mathrm{keV}$ for ${ }^{137} \mathrm{Cs}$, were corrected using the quadratic functional relationship determined in Sec. III.B. Table III summarizes the results for ${ }^{137} \mathrm{Cs}$ and for the ${ }^{134} \mathrm{Cs} /{ }^{137} \mathrm{Cs}$ isotopic ratio. The average per cent differences between the predicted values for ${ }^{137} \mathrm{Cs}$ and ${ }^{134} \mathrm{Cs} /$ ${ }^{137} \mathrm{Cs}$ and the actual measured values were 5.8 and 6.9 , respectively. The counting statistics for ${ }^{137} \mathrm{Cs}$ were generally less than $1 \%$, averaging $0.7 \%$, whereas the counting statistics for ${ }^{134}$ Cs were $5.7 \%$.

IV. CONCLUSIONS

The results obtained using high-resolution gamma-ray spectrometry show that the relative exposures of a large set of heavy-water reactor fuel elements 


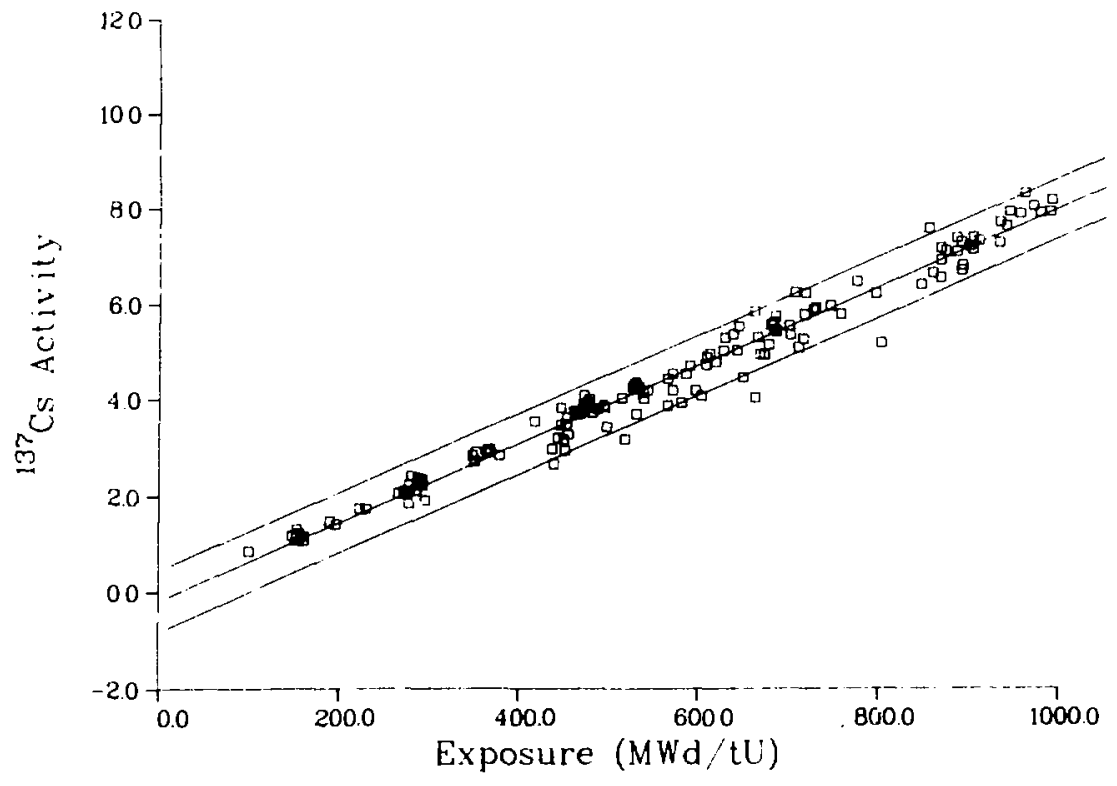

Fig. 6.

Correlation of $137 \mathrm{Cs}$ isotopic concentration with operatordeclared exposure values. Ninety-five per cent confidence bounds have been added to illus trate how well the linear correlation approximates the true correlation.

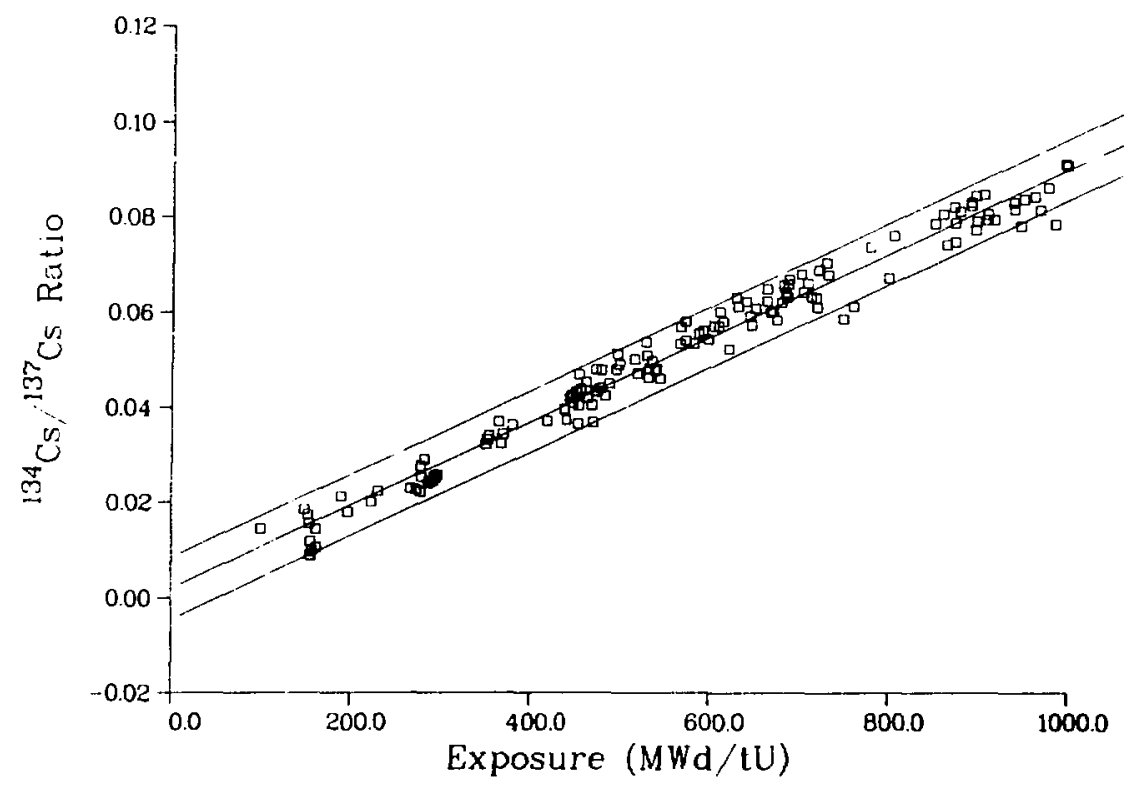

Correlation of the ${ }^{134} \mathrm{Cs} / 137 \mathrm{Cs}$ isotopic ratio with the operator-declared exposure values. Ninety-five per cent confidence bounds have been added to illus trate how well the linear correlation approximates the true correlation. 


\section{SUMMARY OF RESULTS}

Parameter

Average difference between

calculated and measured values

Counting statistics $\underline{137 \text { CS }}$

$5.8 \%$

$0.7 \%$
${ }^{134} \mathrm{Cs} / 137 \mathrm{Cs}$

$6.9 \%$

$5.7 \%$

Equation: Ratio $=a \cdot$ exposure $+b$

STope a

$8.11 \times 10^{-3}$

$8.76 \times 10^{-3}$

Intercept b

$-0.188$

$1.89 \times 10^{-3}$

$\mathrm{R}^{2^{\mathrm{a}}}$

0.9731

0.9759

aThe $R^{2}$ is the correlation coefficient; when multiplied by 100 , it represents the total variation in per cent about the mean of the regression fit.

can be predicted within 5i-7\%. If the measurement geometry is constant, ${ }^{137} \mathrm{Cs}$ can be used to verify the relative exposure values of a set of fuel elements. The ${ }^{134} \mathrm{Cs} /{ }^{137} \mathrm{Cs}$ isotopic ratio appears to be linear with respect to exposure over the measured range of exposures; the isotopic ratio has the advantage of being capable of correcting for differences in self-attenuation or scanning geometry. One factor that contributed to the measured level of uncertainty was the uncertainty associated with the operator-declared exposure values used to obtain the regression 1 ine. Uncertainties in the range of $23-5 \%^{10}$ can normally be expected for operator-declared expesure values.

The relative detection efficiency function :an be applied to identify fuel elements that have broken tension members and $d$ "fferent absorbers in the gammaray beam.

The axial gross gamma-ray profile can be precisely measured using any of the three detector systems; the profiles are indistinguishable. The ionization chamber has a slight advantage because of the speed with which the measurements can be made. 
We wish to thank personnel of TRR for the technical support that made this set of measurements possible. They designed and fabricated the collimation assembly, which functioned perfectly throughout the measurement exercise. S. E. Beach provided the logistical support that was essential for successiul completion of the measurements.

\section{REFERENCES}

1. R. E. Manson, "The Taiwan Research Reactor: A General Description," Chalk River Nuclear Laboratories report CRNL-653, Restricted Distribution (October 1971).

2. J. L. Parker and T. D. Reilly, "Plutonium I sotopic Determination by GammaRay Spectroscopy," Los Alamos Scientific Laboratory report LA-5675-PR (1974), pp. 13-15.

3. T. N. Dragnev, "Intrinsic Self-Calibration of Nondestructive Gamma Spectrometric Measurements (Determination of $U, \mathrm{Pu}$, and Am-241 Isotopic Ratios)," International Atomic Energy Agency report IAEA/STR-60 (1970).

4. R. J.S. Harry, J. K. Aaldijk, and J.P. Braak, "Gamma Spectrometric Determination of Isotopic Composition Without Use of Standards," in Safeguarding Nuclear Materials, Proceedings of the International Symposium on Nuclear Material Safeguards, Vienna, October 20-24, 1975, International Atomic Energy Agency report IAEA-SM-201/66, Vol. II, pp. 235-246.

5. International Atomic Energy Agency Advisory Group Meeting on the Methods and Techniques for NDA Safeguards Measurements on Power Reactor Spent Fue1, AG-241, Vienna, Oc tober 29-November 2, 1979.

6. T. R. Bement and J.R. Phillips, "Evaluation of Relative Detector Efficiency on Sets of Irradiated Fuel Elements," Proceedings of the 1980 DOE Statistical Symposium, Berkeley, Cal ifornia, October 29-31, 1980 (CONF301045) (Apri1 1981).

7. Nuclear Data Sheets 10 (1975).

8. Nuclear Data Sheets 9 (1974).

9. N. R. Draper and H. Smith, Applied Regression Analysis (John Wiley and Sons, Inc., New York, 1966).

10. C. C. Thomas, D. D. Cobb, and C. A. Ostenak, "Spent-Fuel Composition: A Comparison of Predicted and Measured Data," Los Alamos National Laboratory report LA-8764-MS (March 1981). 